\title{
Diplomacy's Paradox in the Law of State Awards
}

\author{
Andreas Nishikawa-Pacher | ORCID: 0000-0001-5149-6294 \\ Doctoral candidate, Vienna School of International Studies; Department of \\ Legal and Constitutional History, University of Vienna, Vienna, Austria \\ andreas.pacher@da-vienna.at
}

Received: 5 October 2020; revised: 26 November 2020; accepted: 13 January 2021

\section{Summary}

Diplomatic gifts are deeply paradoxical: they signal 'peace' between polities constituted by 'power' (peace-and-power paradox); they are exchanged between rulers of contiguous territories so as to momentarily signal a merger of separate entities (paradox of overlapping sovereignties). This essay uses a systems-theoretical approach to uncover this paradox in national laws of state awards. The analysis culminates in a conjectural legal norm prohibiting states to use diplomatic gifts or, to the extreme, a paradoxical norm containing the self-negation and self-prohibition of diplomacy. The essay finally discusses how the peace-and-power paradox and its invisibilisation permeates the whole system of diplomacy.

\section{Keywords}

systems theory - peace - diplomacy - state awards - paradox - sovereignty - gifts

\section{Introduction}

All operations within the diplomatic system communicate sovereignty as nonsovereignty, power as non-power, threat as non-threat. This paradox reflects diplomacy's societal function; namely, the function of enabling friendly relations ('peace') between actors defined by centralised capacities of physical violence ('power'). From a semiotic viewpoint, this peace-and-power interplay finds its operationalisation in the paradox of overlapping sovereignties: the movement of a diplomatic object (e.g., ambassador, panda bear, gift) across 
polities semiotically equals the penetration of one sovereign state into another. ${ }^{1}$ Given that sovereignty conveys the exclusive claim of power over contiguous territories, their overlapping cannot be but structurally improbable - and paradoxical. And yet it often succeeds, but this success comes at the price of an 'irreducible ambiguity'.

Diplomatic gifts are a prime example of this peace-and-power paradox. Prima facie, they seem to signal nothing but peace, a benevolent will to nurture 'friendship between countries, the desire to work together rather than to exist in a state of isolation. ${ }^{3}$ But at the same time, diplomatic gifts appear to be more than 'mere expressions of politeness.' ${ }^{4}$ Their exchange embodies material-ritualistic phenomena connected to a deeper, underlying structure. ${ }^{5}$ And in this underlying structure, all those polities who display 'peace' through gift-giving are in fact constituted by 'power', or by centralised capacities of immense physical violence as amassed through centuries of war and subjugation. ${ }^{6}$ Consequently, diplomatic gifts always seem to contain a trace of threat. 'To refuse to accept [a gift]', says Mauss, ${ }^{7}$ 'is tantamount to declaring war' - and yet, 'whoever receives a gift sells himself' in an act of treason. ${ }^{8}$ The strange anecdote of the foreign heralds who received generous gifts from the local ruler despite just having declared war against the host polity is illustrative of this paradoxical structure. ${ }^{9}$

One may thus sense diplomatic gifts as 'uncertain, incommensurable, and unforeseeable.10 But such statements do not provide a way out of the paradox - nor do they provide a way into it (i.e. to the roots of the systemic indeterminacy).

This essay unveils the peace-and-power paradox behind diplomatic gifts by looking at the laws of state awards; that is, of honorary orders and medals

$1 \quad$ Premising that the diplomatic system reduces the world's complexity via a filter of sovereign semiotics, this essay does not distinguish between diplomacy and public diplomacy. If individual citizens are semiotic signifiers of sovereign polities, then public diplomacy is not about state-to-public relations anymore but remains on the state-to-state level; cf. Ayhan 2019, 68-69.

2 To paraphrase Kustermans 2019, 395.

3 Jansson 2005, 348.

4 Watkins $2008,10$.

5 Cf. Sowerby 2016; Um and Clark 2016; Nexon and Pouliot 2013. War is thus - says Fumerton 1993, 33 - 'the submerged genesis of gift' (as quoted in Jansson 2005, 348).

6 Tilly 1995.

7 Mauss 2000, 13 .

8 de Callières 1983, 153 .

9 Ogdon 1937, 454.

10 Carrió-Invernizzi 2008, 89o. 
which the highest political level bestows on domestic and foreign citizens for meritorious deeds. In the case of foreign recipients, the state award becomes a diplomatic tool. It is here that the diplomatic system's deep structure becomes visible, for the national laws of state awards contain both the component of power and the contrasting one of peace. The legal embodiment of this peaceand-power paradox culminates in the observation that national laws stipulate both the use and the prohibition of honorific orders: polities use state awards and simultaneously problematise them by prohibiting their citizens to accept foreign state awards. Pushed to the extreme, the ultimate end of this norm equals diplomacy's self-elimination.

This essay describes oft-recurring legal norms about state awards, and discusses how they positivise the peace-and-power paradox. It then doctrinally traces how these laws ultimately contain diplomacy's self-negation, a paradox invisibilised in various ways. The essay concludes with a call for diplomatic studies to face, rather than to avoid, the systemic paradox.

\section{Legal Norms on State Awards}

Almost every state possesses the official honorific tool of state award (usually called 'Order')." The majority of countries convey the legal existence of state awards in their constitutions, usually in a catalogue of the Head of State's prerogatives. The polities have also enacted detailed regulations about their awards in dedicated legal acts. These national laws are globally of a similar structure, containing the following oft-recurring rules:

1. The state award is a tool exclusively reserved for the Head of State. In republics, this is usually the President. In monarchies, the grand master behind the awards is a dynastic ruler (e.g., the Japanese Emperor, the Kuwaiti Amir, the Spanish King). ${ }^{12}$ In countries modelled after socialist ideals, the state's highest organ may be a collective body such as the Supreme People's Assembly Presidium in North Korea. ${ }^{13}$ Whatever the

11 One hundred ninety-six out of 204 polities (96 per cent) use state awards. The only countries for which the author found no official evidence of honorific orders are Libya, Marshall Islands, Micronesia, Nauru, Palau, Seychelles, Switzerland and Tuvalu. The sample of 204 polities not only comprises Member States of the United Nations but also the Holy See and a handful of de facto states such as Abkhazia and Somaliland. For more evidence, see the dataset in Pacher 2020.

12 Art. 7 of the Japanese Constitution; Art. 76 of the Kuwaiti Constitution; Art. 62(f) of the Spanish Constitution.

13 Art. 110(16) of the North Korean Constitution. 
polity, it is always the highest political level who serves as the ultimate authority behind every conferral, or as the fons honoris.

2. The award exhibits an iconography of official state symbols.

3. The Head of State retains the right to withdraw a conferred award in case the recipient acts against the interests of the giving state. For instance, the law on honorific orders in Fiji states that the President may at any time 'cancel and annul the award. ${ }^{14}$ Likewise, the Namibian Head of State enjoys the right to revoke any honour once a decorated person 'shows disaffection towards or acts contrary to the national interest'. ${ }^{\prime 5}$ Other countries' laws contain a similarly broad prerogative of the Head of State to revoke awards at any time.

4. The recipient does not acquire full property rights over the state award. In Austria, for example, 'the decoration remains the property of the federal state, and it shall be returned to the Chancellery of Honorific Orders after the decorated person passes away'.16 Property rights over the award are also limited when the medal is exempted from market exchanges: Turkish law bars the award from being 'sold, transferred, donated or reshaped'; 17 and in the United Arab Emirates, while heirs may retain the orders in their possession, 'none of them shall have the right to wear them'. ${ }^{18}$

5. The legally defined reasons for award conferrals are highly contingent. They are usually phrased in vague terms of extraordinary deeds in the interest of the state. The wording in the United States, for instance, is that the President may bestow a medal 'to any person who has made an especially meritorious contribution to (1) the security or national interests of the United States, or (2) world peace, or (3) cultural or other significant public or private endeavors. ${ }^{19}$ Or in the Philippines, anyone 'whose life is worthy of emulation by the Filipino people'20 may receive a state award. Ultimately, anything can serve as the reason for a conferral. The Head of State thus enjoys an extensive scope of discretion in deciding whom to bestow the award. ${ }^{21}$

14 FJ - 1988, Art. 9 (this is the abbreviated label with which the law can be found in the dataset in Pacher 2020 - the same applies to footnotes 15-20, 22-28 and 36).

15 NA -2012 , Art. 3(4).

16 AT $-2001, \S 7(1)$.

17 TR - 1988, Art. 21.

18 AE - 2010, Art. 16.

19 US - 1945, Art. 2(a).

$20 \quad$ PH -2003 , Art. 5(2)(b).

21 This is why state awards can be considered a form of gift: the reason for the bestowal is contingent; there does not have to be a clear one-on-one transaction with a return favour. There is no concrete determination of what happens prior to the bestowal as well as to 
6. State award conferrals are to occur during solemn ceremonies, often on symbolic dates. For example, in Belize, this is each year on Independence Day (the 21st day of September), while in Lithuania, conferrals are to occur on the legendary 'day of Coronation of King Mindaugas. ${ }^{22}$

7. The recipient receives certain privileges - be they material or symbolic. In Rwanda, parks and other public places may be named after the decorated persons, and statues can be erected; ${ }^{23}$ Samoa knows of financial payments, similar to Uzbekistan, where the awarded ones 'receive a one-time monetary reward in the amount of thirty times the minimum wage.' ${ }^{24}$ And China rules broadly that recipients 'shall enjoy preferential treatments during National Celebrations.' ${ }^{25}$

8. Citizens are prohibited to accept foreign state awards (unless their Head of State allows the acceptance as an exception). A usual wording in this direction is, to take one example, 'except with the prior approval of the President in writing, no ... citizen of Zambia shall accept a title of honour, decoration or other dignity from any foreign state. ${ }^{26}$ In Singapore, an unauthorised wearing of foreign insignia makes one 'guilty of an offence' and punishable. ${ }^{27}$ In Portugal, citizens shall request to their Head of State the authorisation of the acceptance of foreign awards, which is to be published in the Official Gazette. ${ }^{28}$

The list generically outlines the most frequent types of recurrent norms as found in national laws on state awards; the exact wording varies from state to state, and not all polities exhibit all of these norms. But together, the catalogue summarises common rules on honorific orders around the world.

What inferences do these recurrent legal norms allow for? With a view towards whether a rule accentuates, on the one hand, the semantics of sovereign

what happens after it, and certainly no enforceable catalogue of conditions that are to be met before one 'earns' the reward. In the end, 'amity' (or, in more political semantics, 'raison d'état') suffices as a reason behind any bestowal.

22 LT - 2002, Art. 10(1); and for Belize: BZ — 2000, Art. 5(1).

23 RW - 2009, Art. 39.

24 UZ - 1994, Art. 5; and for Samoa: ws — 1999, Art. 27.

$25 \mathrm{CN}-2015$, Art. 11.

$26 \quad \mathrm{ZM}-1967$, Art. 5 .

27 SG - 2013, Art. 3(1).

28 PT -2011 , Art. 61(3). 
stateness and exclusive power claims, or, on the other hand, the semantics of interstate togetherness dispensing with sovereign pretensions, one may structure the norms into three clusters. One of the clusters condenses a focus on political power, another one on diplomatic peace, and a final one inextricably entangles both peace and power.

The first four legal norms - that is, the prerogative of the Head of State, the official iconography, the giving state's right to withdraw the award at any time and the limitation of property rights over the award — can be summed up under the cluster of power. This power-centred cluster contains semantic variants of sovereignty and statehood. It emphasises the sole authority of the ruler behind every bestowal and revocation; it reproduces official state symbols and spreads them in material-visual dimensions; it imposes on the subjects restrictive rules on treatment of the benevolent gift. These norms underline that the state award is an artefact of power-constituted sovereignty and sacrosanct statehood.

The legal rules numbered 5 to $7-$ that is, the wide scope of discretion for award bestowals, the solemn ceremony and the granting of privileges together build a cluster of peace. The state can observe the diplomatic system's dynamics and decide spontaneously when and to whom an honorific conferral seems appropriate. The state award is so contingent that it can be used spontaneously to fuel a relation with a further signal of peace and friendship, ${ }^{29}$ without hindrance from cumbersome domestic-legal processes (as opposed to the case of international treaty ratifications, for instance). The signal of having closely observed the foreign, of having valued their deeds highly, of having cherished them so much that one decided to honour them officially is already structurally counterintuitive for a sovereign entity. The actual ceremony underlines this improbably benign diplomatic character even more, for it ritually generates a symbol of shared togetherness, of momentarily merged sovereignties, if not of a (structurally improbable) debasement of the self, conjoined with the (structurally improbable) elevation of the other. ${ }^{30}$ The conferral of additional privileges, often lasting for a lifetime, emphasises the giving state's commitment towards its peace-loving behaviour even beyond the unique moment. All these norms signal peace while invisibilising power — for they invisibilise the

\footnotetext{
29 Cf. Bjola and Kornprobst 2013, 123; Söderström, Åkebo, and Jarstad 2020. Some bestowals may not seem to signal amity but rather enmity (e.g., when they honour dissidents), which illustrates the indeterminacy behind the peace-and-power paradox. 
world political structure of separateness and estrangement, ${ }^{31}$ they invisibilise that both the giver and the recipient semiotically equal hermetically shut sovereign entities.

In the first cluster of legal norms, the state award appeared as a 'form' for the 'medium' of power, while in the second cluster, the state award appeared as a 'form' for the 'medium' of peace. ${ }^{32}$ The final legal rule (number 8) combines the two preceding clusters: a state prohibits its citizens to accept foreign state awards unless the Head of State allows it under exceptional circumstances. This norm is subsumable under neither purely peace nor purely power, but rather comprise both aspects inextricably. It first conforms to the structure of sovereignty because it bars a semiotic signifier of a foreign polity (the foreign award) from entering the country. But in a second step, it relativises this power-conforming rule by allowing the semiotic entrance of foreign awards if the Head of State grants an exemption.

Moreover, this norm not only reflects, but also invisibilises, the diplomatic peace-and-power paradox: it hides the paradox behind a sequence of 'powerfirst' (starting with a general prohibition of foreign signifiers) and 'peace-later' (proceeding with the allowance of selected signifiers). The norm thus conceals the paradox through a temporal device (prior vs. posterior) and a social device (all countries vs. selected countries) but it cannot fully eliminate diplomacy's structural indeterminacy, an indeterminacy oscillating between the sovereign apprehension of a foreign threat and the display of interstate friendship. ${ }^{33}$

\section{$4 \quad$ Diplomacy's Self-negation}

The paradox lies even deeper. It is not merely about state awards but, rather, reflects the deep structure of the diplomatic system. Behind the indeterminacy of the paradox hides diplomacy's self-negation.

This becomes visible once the domestic legal norm that prohibits citizens to accept foreign state awards is translated into the higher abstraction of the international sphere. With this doctrinal step, the addressee of the prohibition changes from a polity's subjects to the totality of sovereign states. The norm

\footnotetext{
31 Der Derian 1987; Sharp 2009.

32 On the systems-theoretical notion of (an abstract, invisible) 'medium' that attaches itself onto (concrete, visible) 'forms', see Luhmann 2012, 113-120; Albert 2016, 57.

Bjola 2013 .
} 
would thus be read not as a prohibition of individuals to accept foreign state awards, but as a prohibition of states to give state awards to foreign subjects.

With greater abstraction, the consequence becomes even more far-reaching, for if one categorised the state award as a gift exchanged between sovereigns, then the principle would be one prohibiting states to exchange diplomatic gifts. But if diplomatic gifts signal peace between sovereigns, and if signals of peace between sovereign power holders are the sole domain of diplomacy, then the (mutated) norm equals, to the extreme, a prohibition of states to use diplomacy. But where would such a prohibition of diplomacy come from? As all international norms are made by the states themselves through interstate relational practices that aim to foster peace - that is, through diplomacy that conjectural norm would itself draw from diplomatic practices of peace. The norm that prohibits diplomacy thus arises from diplomacy itself; it is a peace-generated norm that prohibits peace. And this self-negation is the ultimate end of the paradox, an end hidden in simple domestic rules about honorific orders.

\section{The Invisibilisation of the Paradox}

All systems are grounded in a paradox which they invisibilise. ${ }^{34}$ This is why it requires theoretical labour (here: legal-doctrinal efforts) to uncover this fundamental indeterminacy.

With regards to state award laws, the diplomatic system knows of various layers of invisibilisation. The case of state awards exhibits at least three such 'tricks'. One is variation: there is a plurality of states with a plurality of diplomatic tools and a plurality of state award laws and thus a plurality of combinations of legal norms, some of which may contain the peace-and-power paradox visibly while others hide it more effectively. ${ }^{35}$ Another device to invisibilise the paradox occurs through a temporal unfolding: a sequence of general prohibition first (power), followed by a selected allowance later (peace). For example, at time $t_{1}$, countries enact a law prohibiting citizens to accept foreign awards, but allow an exception under certain conditions at time $t_{2}$ - as if what they first apprehended as enmity turns later out to be amity. Cases when 'any citizen ... shall obtain permission of the Government' prior to 'receiving

34 Luhmann 1995a, 33; 1995b.

35 Luhmann 2012, 275-283. 
any honours or decorations from a foreign country'36 belong to this category. In other words, the two opposing values of amity and enmity are identical - and herein lies the paradox; but by claiming the foreign award to signify enmity at $t_{1}$ but amity under certain conditions at $t_{2}$, the paradox becomes invisibilised. A third device uses a social unfolding of the paradox; that is, the prohibition to accept foreign state awards from most countries but not from some other ones. For instance, Australia bans the acceptance of honours from other sovereigns (for they may signify foreign power) unless the honorific order comes from a list of countries specified in a regulation (as if they then ceased to signify foreign power). ${ }^{37}$

These are mere assumptions about how the diplomatic system invisibilises ${ }^{38}$ the simultaneous presence of power (enmity, threat) and peace (amity, cooperation). There may be other devices of invisibilisation such as the strategic elicitation of positive emotions ${ }^{39}$ - which is especially pertinent in the case of state awards. A more systematic approach to such de-paradoxification techniques, and the question why scholars of diplomacy often fall into the trap of this invisibilisation, must remain open issues for future research.

There is a structural, ineliminable indeterminacy behind state awards, an indeterminacy pointing to the diplomatic system's paradoxical function of enabling 'peace' between holders of 'power'. It is for this reason that 'the aim of peace [cannot] be enforced ... without the threat of war'.40 As a consequence, in any diplomatic gift exchange, there will always be mistrust, always an apprehension of a foreign animus dominandi, always a parasitic trace of power and centralised capacities of physical violence. War is the ultimate constituent of diplomatic gifts, for war looms behind all diplomacy.

There is a temptation for diplomatic theories to avoid this paradox simply because the diplomatic system itself conceals it. It would be more fruitful not to circumvent the paradox but, rather, to uncover it and its invisibilisation in every single diplomatic communication. In the accreditation of an ambassador, in a conflictual argument in multilateral organisations, in the negotiation

36 A wording from a Nepalese law (cf. NP - 2007, Art. 19 in the dataset mentioned in footnote 14).

37 Governor-General of the Commonwealth of Australia 2019.

38 Or 'reconciles', 'harmonises', 'exceptionalises', to use terms from Kornprobst 2019, 30.

39 McConnell 2018; Wong 2020, 84.

$40 \quad$ Hippler and Vec 2015, 15. 
of peace treaties, in the declaration of war and in the exchange of diplomatic gifts; in all these acts one can find the peace-and-power paradox of overlapping sovereignties.

\section{Bibliography}

Albert, Mathias. A Theory of World Politics (Cambridge: Cambridge University Press, 2016).

Ayhan, Kadir Jun. 'The Boundaries of Public Diplomacy and Nonstate Actors: A Taxonomy of Perspectives'. International Studies Perspectives 20 (1) (2019), 63-83. DoI 10.1093/isp/ekyo1o.

Bjola, Corneliu. 'Understanding Enmity and Friendship in World Politics'. The Hague Journal of Diplomacy 8 (1) (2013), 1-20. DoI 10.1163/1871191X-12341242.

Bjola, Corneliu and Markus Kornprobst. Understanding International Diplomacy (London: Routledge, 2013).

Carrió-Invernizzi, Diana. 'Gift and Diplomacy in Seventeenth-Century Spanish Italy'. Historical Journal 51 (4) (2008), 881-899. DOI 10.1017/Soo18246Xo8007115.

de Callières, François. The Art of Diplomacy (New York: Holmes and Meier, 1983).

Der Derian, James. On Diplomacy: A Genealogy of Western Estrangement (Oxford: Blackwell, 1987).

Fumerton, Patricia. Cultural Aesthetics (Chicago: University of Chicago Press, 1993).

Governor-General of the Commonwealth of Australia. Accepting and Wearing of Foreign Awards'. 1 December 2019. https://web.archive.org/web/20210113095502/ https://www.gg.gov.au/australian-honours-and-awards/accepting-and-wearing-foreign -awards-australians.

Hippler, Thomas and Miloš Vec. Paradoxes of Peace in Nineteenth Century Europe (Oxford: Oxford University Press, 2015).

Jansson, Maija. 'Measured Reciprocity: English Ambassadorial Gift Exchange in the 17th and 18th Centuries'. Journal of Early Modern History 9 (3) (2005), 348-370. DOI 10.1163/157006505775008491.

Kornprobst, Markus. Co-Managing International Crises (Cambridge: Cambridge University Press, 2019).

Kustermans, Jorg. 'Gift-Giving as a Source of International Authority'. Chinese Journal of International Politics 12 (3) (2019), 395-426. DOI 10.1093/cjip/pozoog.

Luhmann, Niklas. Social Systems (Stanford: Stanford University Press, 1995a).

Luhmann, Niklas. 'The Paradoxy of Observing Systems'. Cultural Critique 31 (1995b), 37-55. DOI 10.2307/1354444.

Luhmann, Niklas. Theory of Society (Stanford: Stanford University Press, 2012). 
Mauss, Marcel. The Gift (New York: Norton, 200o).

McConnell, Fiona. 'Performing Diplomatic Decorum'. International Political Sociology 12 (4) (2018), 362-381. DOI 10.1093/ips/olyo21.

Neumann, Iver B. 'Self and Other in International Relations'. European Journal of International Relations 2 (2) (1996), 139-174. DOI 10.1177\%2F1354066196002002001.

Nexon, Daniel H. and Vincent Pouliot. “Things of Networks": Situating ANT in International Relations'. International Political Sociology 7 (3) (2013), 342-345. DOI 10.1111/ips.12026_4.

Nordin, Astrid H.M. and Graham M. Smith. 'Reintroducing Friendship to International Relations'. International Relations of the Asia-Pacific 18 (2018), 369-396. DOI 10.1093/ irap/lcyol1.

Ogdon, Montell. 'The Growth of Purpose in the Law of Diplomatic Immunity'. American Journal of International Law 31 (3) (1937), 449-465. DOI 10.2307/2190456.

Pacher, Andreas. 'The Ritual Creation of Political Symbols'. British Journal of Politics and International Relations 20 (4) (2018), 880-897. DO 10.1177/1369148118786043.

Pacher, Andreas. 'Evidence on the Existence of State Awards' (Dataset). Open Science Framework (2020). DOI 10.17605/OSF.IO/AKZT8.

Sharp, Paul. Diplomatic Theory of International Relations (Cambridge: Cambridge University Press, 2009).

Söderström, Johanna, Malin Åkebo and Anna K. Jarstad. 'Friends, Fellows, and Foes: A New Framework for Studying Relational Peace'. International Studies Review (online first, 2020). DOI 10.1093/isr/viaao33.

Sowerby, Tracey A. 'Early Modern Diplomatic History'. History Compass 14 (9) (2016), 441-456. DOI 10.1111/hic3.12329.

Tilly, Charles. Coercion, Capital, and European States, AD 990-1992 (Cambridge: Blackwell, 1995).

Um, Nancy and Leah R. Clark. 'The Art of Embassy: Situating Objects and Images in the Early Modern Diplomatic Encounter'. Journal of Early Modern History 20 (1) (2016), 3-18. DOI 10.1163/15700658-12342487.

Watkins, John. 'Toward a New Diplomatic History of Medieval and Early Modern Europe'. Journal of Medieval and Early Modern Studies 38 (1) (2008), 1-14. DOI 10.1215/10829636-2007-016.

Wong, Seanon S. 'Mapping the Repertoire of Emotions and Their Communicative Functions in Face-to-Face Diplomacy'. International Studies Review 22 (2020), 77-97. DOI 10.1093/isr/viyo79.

\section{Andreas Nishikawa-Pacher}

is a PhD candidate at the Vienna School of International Studies in a joint doctoral programme with the University of Vienna. 